\title{
Synthesis of $\beta-\mathrm{Co}(\mathrm{OH})_{2}$ Platelets by Precipitation and Hydrothermal Methods
}

\author{
Hiroshi ITAHARA, Shin TAJIMA and Toshihiko TANI \\ Toyota Central Research and Development Laboratories, Inc., 41-1, Yokomichi, Nagakute, Aichi-gun, Aichi 480-1192
}

\author{
沈殿法及び水熱法による板状 $\beta$ - $\mathrm{Co}(\mathrm{OH})_{2}$ 結晶の合成 \\ 板原 浩·田島 伸·谷 俊彦 \\ (株)豊田中央研究所, 480-1192 愛知県愛知郡長久手町大字長湫字横道 41-1
}

\begin{abstract}
Hexagonal $\beta-\mathrm{Co}(\mathrm{OH})_{2}$ platelets with high crystallinity $(0.3-10 \mu \mathrm{m}$ in average diameter and $\sim 5$ in aspect ratio) have been synthesized. The platelets of $0.3-0.5 \mu \mathrm{m}$ in diameter were prepared by a precipitation method, and their sizes were affected by the cobalt ion concentration in the suspensions. Adding rate of precipitant, stirring rate of solution, and aging temperature gave little effect on their morphologies. The platelets with well developed facets were synthesized with high reproducibility, when chloride salt was used as a Cosource and the suspension was aged at room temperature for $86.4 \mathrm{ks}$. The platelets have been enlarged up to 5-10 $\mu \mathrm{m}$ with maintaining morphology (hexagonal shape, $\sim 5$ in aspect ratio) by hydrothermal treatment (at $393 \mathrm{~K}$ for $86.4 \mathrm{ks}$ in $12 \mathrm{~mol} / \mathrm{dm}^{3} \mathrm{NaOH}$ aqueous solution).
\end{abstract}

[Received May 28, 2002; Accepted September 22, 2002]

Key-words : $\beta$ - $\mathrm{Co}(\mathrm{OH})_{2}, \mathrm{CoO}(\mathrm{OH}), \mathrm{Co}_{3} \mathrm{O}_{4}$, Platelet, Template, Precipitation, Hydrothermal, Textured ceramic

\section{Introduction}

Texture control of functional ceramics by the templated grain growth (TGG) and reactive TGG (RTGG) methods has received increasing attention for their capability to enhance bulk-material properties without using large single crystals. ${ }^{1)-5}$ ) The preparation of anisomeric template particles is one of the key technologies for the application of the processing methods to the fabrication of devices. Molten salt synthesis has been employed for the preparation of template materials or their precursors (eg. $\mathrm{Bi}_{4} \mathrm{Ti}_{3} \mathrm{O}_{12}, \mathrm{Sr}_{3} \mathrm{Ti}_{2} \mathrm{O}_{7}$, $\mathrm{Ba}_{6} \mathrm{~T}_{17} \mathrm{O}_{40}$, et al.) for the textured piezoelectric and dielectric oxide polycrystals. ${ }^{6)-10)}$ The precipitation method and the hydrothermal treatment would be less expensive techniques than the molten salt synthesis for the system because of the lower temperatures for crystal growth. Hirota et al. used $\alpha-\mathrm{Fe}_{2} \mathrm{O}_{3}$ platelets, which had been prepared by the hydrothermal synthesis, for the fabrication of highly textured $\mathrm{Mn}-\mathrm{Zn}$ ferrite ceramics for a magnetic head. ${ }^{11)}$

Recently, authors have reported ${ }^{12}$ ) that highly grainoriented $\mathrm{NaCo}_{2} \mathrm{O}_{4}$ polycrystalline ceramic was prepared by the RTGG process using $\mathrm{Co}_{3} \mathrm{O}_{4}$ platelets as templates. Cobalt hydroxides $\left(\mathrm{Co}(\mathrm{OH})_{2}\right.$ and $\left.\mathrm{CoO}(\mathrm{OH})\right)$ would also be useful materials as reactive templates (precursors) for the recently reported thermoelectric cobaltites such as $\mathrm{NaCo}_{2} \mathrm{O}_{4}{ }^{13), 14)}$ and $\mathrm{Ca}_{2} \mathrm{Co}_{2} \mathrm{O}_{5}{ }^{15}$ ) because these hydroxides have hexagonal layered structures having lattice matching with cobaltite materials. The layered crystal structures of the complex cobalt oxides contribute to anisotropic thermoelectric properties, ${ }^{14)}$ so that the fabrication method of highly-textured ceramics would be a key technology in the mass-production of these materials for thermoelectric device applications.

$\mathrm{Co}(\mathrm{OH})_{2}$ has been used for important applications, such as additives for alkaline batteries ${ }^{16)}$ and precursors for heterogeneous catalysts. ${ }^{17)}$ Most of the past works were limited in the prevention of oxidation of cobalt hydroxides for the improvement of battery performance. ${ }^{16)}$ Anisometric morphology and high crystallinity are both required for the template to be used in the RTGG process, because the process includes good alignment of template particles and in-situ topotaxial and/or epitaxial formation and growth of the product material. The control of both morphology and cry- stallinity of $\mathrm{Co}(\mathrm{OH})_{2}$ during the synthesis and growth, however, has not been fully established yet, especially in the point of use for a reactive template. In this study, $\mathrm{Co}(\mathrm{OH})_{2}$ platelets were synthesized by precipitation and hydrothermal methods, and the morphology and crystallinity were examined.

\section{Experimental}

2.1 Effect of Co-source materials

Reagent-grade $\mathrm{CoCl}_{2} \cdot 6 \mathrm{H}_{2} \mathrm{O}$ (99.99\%, Kojundo Chemical Lab. Co., Ltd.), $\mathrm{Co}\left(\mathrm{NO}_{3}\right)_{2} \cdot 6 \mathrm{H}_{2} \mathrm{O}(99.99 \%$, Kojundo Chemical Lab. Co., Ltd.), and $\mathrm{NaOH}$ (99.9\%, Wako Pure Chemical Industries Ltd.) were used without further purification. Distilled water was used after outgassing by $\mathrm{N}_{2}$ bubbling in order to prevent undesirable oxidation of precipitates due to dissolved oxygen.

An aqueous solution of $\mathrm{NaOH}$ (the precipitant, $0.20 \mathrm{~mol} /$ $\mathrm{dm}^{3}$ ) was added dropwise to aqueous solutions of $\mathrm{CoCl}_{2}$. $6 \mathrm{H}_{2} \mathrm{O}$ and $\mathrm{Co}\left(\mathrm{NO}_{3}\right)_{2} \cdot 6 \mathrm{H}_{2} \mathrm{O}\left(0.10 \mathrm{~mol} / \mathrm{dm}^{3}\right)$. The suspensions (total amount: $0.90 \mathrm{dm}^{3}$ ) were aged in a glass flask $\left(1.00 \mathrm{dm}^{3}\right)$ at room temperature for $86.4 \mathrm{ks}$ with $\mathrm{N}_{2}$ bubbling. The precipitates were separated, washed with distilled water, and dried in $\mathrm{N}_{2}$ flow.

The precipitates were characterized by powder X-ray diffraction (XRD, Model RINT2100, Rigaku Co.) and scanning electron microscopy (SEM, Model Sigma-V, Akashi Ltd.).

2.2 Observation of crystal growth during aging

An aqueous solution of $\mathrm{NaOH}$ (the precipitant, $0.20 \mathrm{~mol} /$ $\mathrm{dm}^{3}$ ) was added dropwise to an aqueous solution of $\mathrm{CoCl}_{2}$. $6 \mathrm{H}_{2} \mathrm{O}\left(0.10 \mathrm{~mol} / \mathrm{dm}^{3}\right)$. The addition of the $\mathrm{NaOH}$ solution was completed in about $180 \mathrm{~s}$. Then, the suspension (initial amount: $\left.2.70 \mathrm{dm}^{3}\right)$ was aged in a glass flask $\left(3.00 \mathrm{dm}^{3}\right)$ at room temperature with stirring at $160 \mathrm{rpm}$ and $\mathrm{N}_{2}$ bubbling. During aging, a part of the suspension (about $20 \times 10^{-3}$ $\left.\mathrm{dm}^{3}\right)$ was sampled after given aging time $(0.36,1.8,3.6$, $10.8,21.6$ and $86.4 \mathrm{ks}$ ) and the precipitates in each suspension were separated.

Particle size distribution (PSD) was determined by a laser scattering particle size analyzer (Model LA910, Horiba Ltd.). The precipitates (about $100 \mathrm{mg}$ ) were dispersed into an aqueous solution (about $30 \times 10^{-3} \mathrm{dm}^{3}$ ) of so- 
dium hexametaphosphate $(0.1$ mass $\%)$ for the measurement of size distribution.

\subsection{Examination of precipitation conditions}

An aqueous solution of $\mathrm{NaOH}$ (the precipitant, 0.20 or $0.05 \mathrm{~mol} / \mathrm{dm}^{3}$ ) was added dropwise to an aqueous solution of $\mathrm{CoCl}_{2} \cdot 6 \mathrm{H}_{2} \mathrm{O}\left(0.10\right.$ or $\left.0.025 \mathrm{~mol} / \mathrm{dm}^{3}\right)$. Adding rate of $\mathrm{NaOH}$ solution and stirring rate of the suspension were varied from 0.083 to $0.25 \times 10^{-3} \mathrm{dm}^{3} / \mathrm{s}$ and from 40 to 320 rpm, respectively. The suspensions (total amount: 2.70 $\left.\mathrm{dm}^{3}\right)$ were aged in a glass flask $\left(3.00 \mathrm{dm}^{3}\right)$ for $86.4 \mathrm{ks}$ at room temperature or $323 \mathrm{~K}$ with $\mathrm{N}_{2}$ bubbling. The precipitates were separated, washed with distilled water, and dried in $\mathrm{N}_{2}$ flow.

2.4 Hydrothermal treatment

The powder specimen of $\mathrm{Co}(\mathrm{OH})_{2}$ of $0.3 \mu \mathrm{m}$ in diameter (about $0.5 \mathrm{~g}$ ) prepared by the precipitation (starting solutions: $0.20 \mathrm{~mol} / \mathrm{dm}^{3} \mathrm{NaOH}$ and $0.10 \mathrm{~mol} / \mathrm{dm}^{3} \mathrm{CoCl}_{2} \cdot 6 \mathrm{H}_{2} \mathrm{O}$, aging conditions: room temperature, $160 \mathrm{rpm}, 86.4 \mathrm{ks}, \mathrm{N}_{2}$ bubbling) was dispersed into an aqueous solution of $\mathrm{NaOH}$ $\left(12 \mathrm{~mol} / \mathrm{dm}^{3}, 50 \times 10^{-3} \mathrm{dm}^{3}\right)$. The suspension was confined in a Teflon-lined autoclave (capacity $100 \times 10^{-3} \mathrm{dm}^{3}$ ) and heat-treated at $393 \mathrm{~K}$ for $86.4 \mathrm{ks}$. The autoclave was not equipped with a vent valve and thus a small amount of air was remained in the autoclave. The heat-treated specimen was separated, washed with distilled water, and dried in $\mathrm{N}_{2}$ flow.

\section{Results and discussion}

\subsection{Effect of Co-source materials}

$\beta$ - $\mathrm{Co}(\mathrm{OH})_{2}$ platelets were obtained with high reproducibility by using $\mathrm{CoCl}_{2} \cdot 6 \mathrm{H}_{2} \mathrm{O}$ as $\mathrm{Co}$-source. Figure 1 gives an SEM micrograph of the prepared platelets having a hexagonal shape, an average diameter of $\sim 0.3 \mu \mathrm{m}$, and an aspect ratio of $\sim 5$. The insufficient $\mathrm{N}_{2}$ bubbling gave $\beta$ - $\mathrm{Co}(\mathrm{OH})_{2}$ with distorted facets and a small amount of $\mathrm{Co}_{3} \mathrm{O}_{4}$ phase detected. Sufficient $\mathrm{N}_{2}$ bubbling was required for high crystallinity because $\beta$ - $\mathrm{Co}(\mathrm{OH})_{2}$ is readily oxidized by dissolved oxygen.

The use of $\mathrm{Co}\left(\mathrm{NO}_{3}\right)_{2} \cdot 6 \mathrm{H}_{2} \mathrm{O}$ as Co-source gave a low reproducibility of $\beta$ - $\mathrm{Co}(\mathrm{OH})_{2}$ and platelets of $\mathrm{CoO}(\mathrm{OH})$ and $\mathrm{Co}_{3} \mathrm{O}_{4}$ tended to form instead. The use of nitrate is considered to promote oxidation reaction in the suspension, so that it would lead to crystals composed of $\mathrm{Co}$ with a higher valence number, such as in $\mathrm{CoO}(\mathrm{OH})$ and $\mathrm{Co}_{3} \mathrm{O}_{4}$, rather than in $\beta-\mathrm{Co}(\mathrm{OH})_{2}$. The precipitation environment (starting materials, species of existing ions, $\mathrm{pH}$, atmosphere, existence of oxidizing agents) can affect the crystalline phase of resultant precipitates. Figure 2 gives SEM micrographs of $\mathrm{CoO}(\mathrm{OH})$ and $\mathrm{Co}_{3} \mathrm{O}_{4}$ platelets prepared typically from the

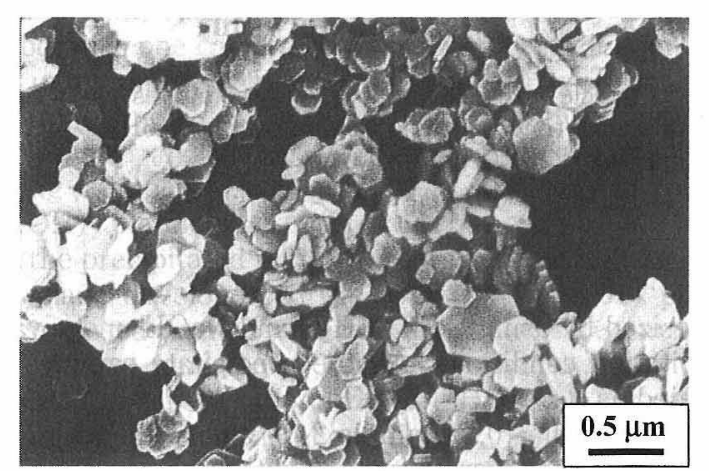

Fig. 1. SEM micrograph of $\beta$ - $\mathrm{Co}(\mathrm{OH})_{2}$ prepared by the precipitation method with the use of $\mathrm{CoCl}_{2} \cdot 6 \mathrm{H}_{2} \mathrm{O}\left(0.10 \mathrm{~mol} / \mathrm{dm}^{3}\right)$ and $\mathrm{NaOH}\left(0.20 \mathrm{~mol} / \mathrm{dm}^{3}\right)$ as starting solutions. suspensions using $\mathrm{Co}\left(\mathrm{NO}_{3}\right)_{2} \cdot 6 \mathrm{H}_{2} \mathrm{O}$ as Co-source, where the suspensions were aged for $259.2 \mathrm{ks}$ at room temperature, stirred vigorously, without $\mathrm{N}_{2}$ bubbling. $\mathrm{CoO}(\mathrm{OH})$ and $\mathrm{Co}_{3} \mathrm{O}_{4}$ are also candidate templates for highly textured thermoelectric cobaltite ceramics, however, crystallinity was low for the particles prepared in this study. Preparation conditions of $\beta$ - $\mathrm{Co}(\mathrm{OH})_{2}$ by using $\mathrm{CoCl}_{2} \cdot 6 \mathrm{H}_{2} \mathrm{O}$ were examined in detail as described in the following sections.

\subsection{Crystal growth in precipitation method}

Table 1 summarizes the characteristics of the precipitates sampled after various aging time, which were prepared by using $\mathrm{CoCl}_{2} \cdot 6 \mathrm{H}_{2} \mathrm{O}$ and $\mathrm{NaOH}$ solutions. Precipitates were formed right after the addition of the precipitant. Because of the extremely low solubility of $\mathrm{Co}(\mathrm{OH})_{2}$ (solubility product: $\left.3.16 \times 10^{-15} \mathrm{~mol}^{3} / \mathrm{dm}^{9}\right)$, it is consiclered that $\mathrm{Co}(\mathrm{OH})_{2}$ was immediately and completely deposited by the addition of precipitant.

The suspension colored blue in the beginning (samples $1-1$ and $1-2$, aged for 0.36 and $1.8 \mathrm{ks}$ ), and then gradually changed its color to pink with aging time (1-3 to $1-6$, aged
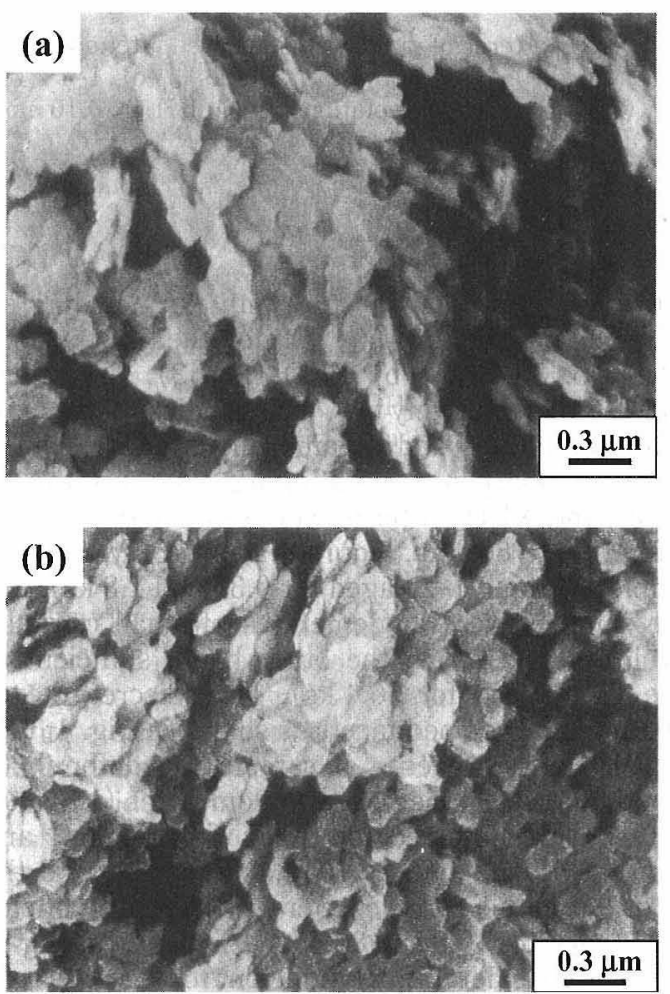

Fig. 2. SEM micrographs of (a) $\mathrm{CoO}(\mathrm{OH})$, and (b) $\mathrm{Co}_{3} \mathrm{O}_{4}$ prepared by using $\mathrm{Co}\left(\mathrm{NO}_{3}\right)_{2} \cdot 6 \mathrm{H}_{2} \mathrm{O}\left(0.10 \mathrm{~mol} / \mathrm{dm}^{3}\right)$ and $\mathrm{NaOH}(0.20$ $\left.\mathrm{mol} / \mathrm{dm}^{3}\right)$ as starting solutions.

Table 1. Characteristics of Precipitates Sampled after Different Aging Time

\begin{tabular}{ccccc}
\hline \multirow{2}{*}{$\begin{array}{c}\text { Sample } \\
\text { name }\end{array}$} & $\begin{array}{c}\text { Aging time } \\
\text { /ks }\end{array}$ & Color of suspension & \multicolumn{2}{c}{ Characteristics of precipitates } \\
\cline { 4 - 5 } & & & Crystalline phase & $\begin{array}{c}\text { Ave. particle } \\
\text { size / } \mu \mathrm{m}\end{array}$ \\
\hline $1-1$ & 0.36 & Vivid blue & $\beta-\mathrm{Co}(\mathrm{OH})_{2}$ & $32.1^{*}$ \\
$1-2$ & 1.8 & Bluish purple & $\beta-\mathrm{Co}(\mathrm{OH})_{2}$ & $30.7^{*}$ \\
$1-3$ & 3.6 & Purple & $\beta-\mathrm{Co}(\mathrm{OH})_{2}$ & $35.2^{*}$ \\
$1-4$ & 10.8 & Pinkish purple & $\beta-\mathrm{Co}(\mathrm{OH})_{2}$ & 0.31 \\
$1-5$ & 21.6 & Pink & $\beta-\mathrm{Co}(\mathrm{OH})_{2}$ & 0.32 \\
$1-6$ & 86.4 & Pink & $\beta-\mathrm{Co}(\mathrm{OH})_{2}$ & 0.29 \\
\hline
\end{tabular}

* Average size of agglomerated particles 


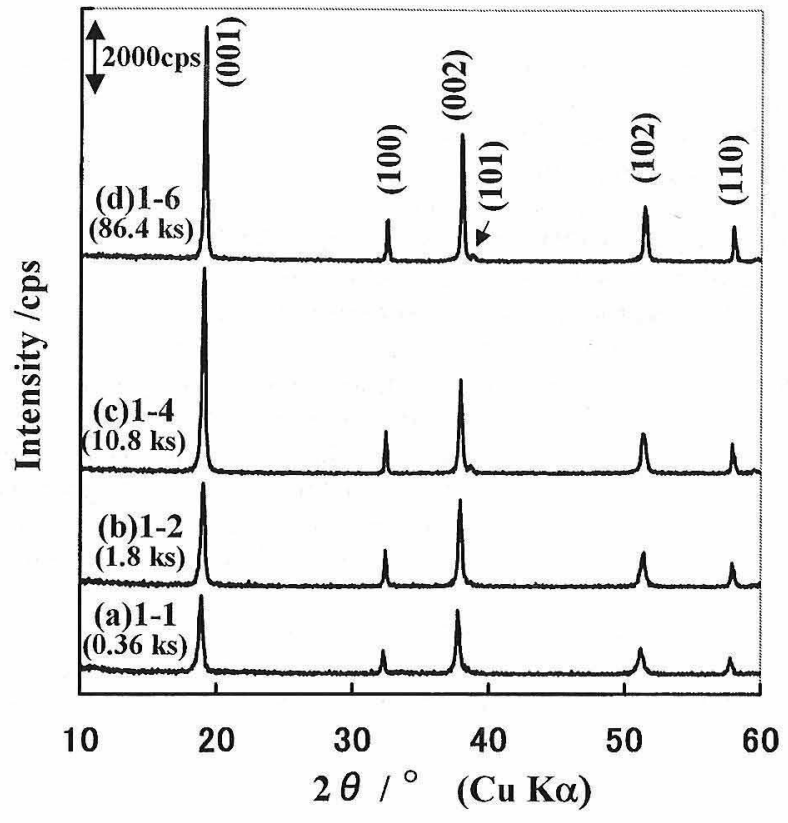

Fig. 3. XRD patterns of precipitates sampled after different aging time: (a) $1-1$ (0.36 ks), (b) $1-2(1.8 \mathrm{ks})$, (c) $1-4(10.8 \mathrm{ks})$ (d) 1-6 (86.4 ks). Starting solutions: $\mathrm{CoCl}_{2} \cdot 6 \mathrm{H}_{2} \mathrm{O}\left(0.10 \mathrm{~mol} / \mathrm{dm}^{3}\right)$ and $\mathrm{NaOH}\left(0.20 \mathrm{~mol} / \mathrm{dm}^{3}\right)$.

for 3.6 to $86.4 \mathrm{ks})$. All the precipitates, including sample 1-1 (aged for $3.6 \mathrm{ks}$ ), were identified as $\beta$-Co $(\mathrm{OH})_{2}$ (JCPDS No. 30-0443) by XRD (Fig. 3). Crystallinity of sample 1-1 was relatively low, which indicates the existence of small crystallites and/or amorphous phase. Diffraction peaks were sharpened with aging time up to $10.8 \mathrm{ks}$. However, the XRD patterns were similar for the samples aged for 10.8 to $86.4 \mathrm{ks}$. Figure 4 shows SEM micrographs of samples 1-1 and 1-2 (aged for 0.36 and $1.8 \mathrm{ks}$ ). The large-size samples were agglomerates of small crystals with undeveloped facets. On the other hand, sufficiently aged sample (1-6, aged for $86.4 \mathrm{ks})$, gave discrete hexagonal platelets with developed facets as shown in Fig. 1. Figure 5 gives PSD measurements of samples aged for $0.36,1.8$, 10.8 , and $86.4 \mathrm{ks}$. Rather large agglomerates $(10-100 \mu \mathrm{m}$ in diameter) were detected for the samples of $1-1$ and $1-2$ (aged for 0.36 and $1.8 \mathrm{ks}$ ). The average size and the size distribution of the particles were similar for samples 1-4 and 1-6 (aged for 10.8 and $86.4 \mathrm{ks}$ ). Thus, the aging time of $86.4 \mathrm{ks}$ was considered to be sufficient for the preparation of discrete platelets with developed facets.

In general, the size and the morphology of crystals depend on both the number of nucleus and the growth mechanism. The suspension would give the primary nuclei of $\beta$ - $\mathrm{Co}(\mathrm{OH})_{2}$ formed immediately because of the low solubility of $\beta$ - $\mathrm{Co}(\mathrm{OH})_{2}$. The XRD patterns of the precipitates indicate, however, that the suspension contained numerous amorphous crystallites at the early stage of precipitation. Thus, the nuclei of $\beta$ - $\mathrm{Co}(\mathrm{OH})_{2}$ grew gradually by means of solution-reprecipitation, where the amorphous crystallites were incorporated into the nuclei, and thus the facets of the crystals were developed. Furthermore, the ultimate sizes of the crystals were determined by the number of primary nucleus dependent on the early stage of precipitation in this system.

3.3 Effects of the precipitation conditions on $\beta$ $\mathrm{Co}(\mathrm{OH})_{2}$ prepared from $\mathrm{CoCl}_{2} \cdot 6 \mathrm{H}_{2} \mathrm{O}$

Table 2 summarizes the characteristics of precipitates
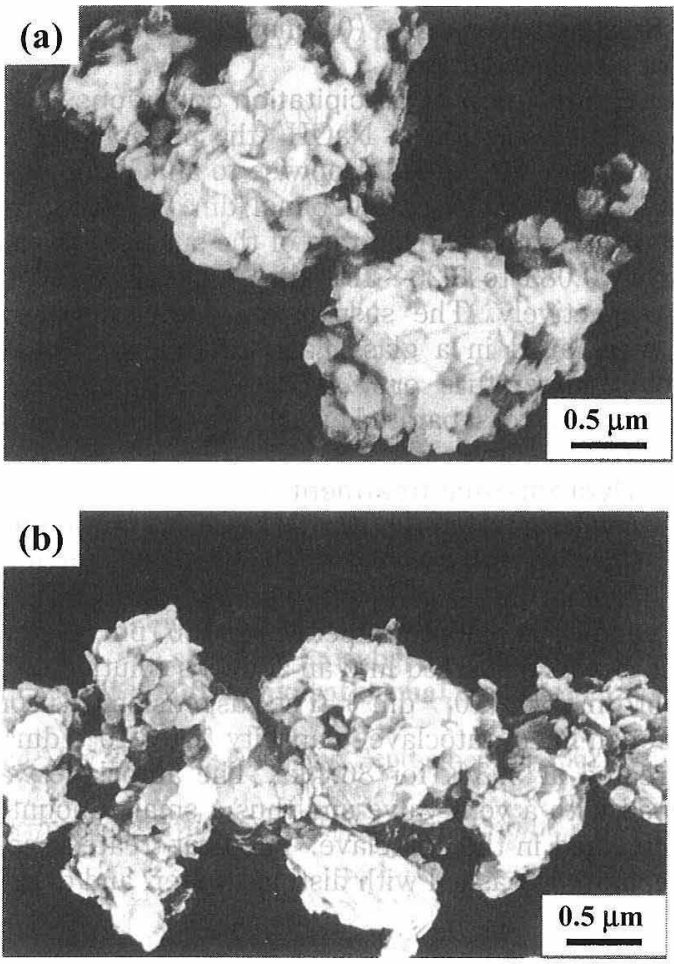

Fig. 4. SEM micrographs of $\beta$-Co $(\mathrm{OH})_{2}$ sampled after different aging time: (a) 1-1 (aging time: $0.36 \mathrm{ks})$, (b) $1-2(1.8 \mathrm{ks})$. Starting solutions: $\mathrm{CoCl}_{2} \cdot 6 \mathrm{H}_{2} \mathrm{O}\left(0.10 \mathrm{~mol} / \mathrm{dm}^{3}\right)$ and $\mathrm{NaOH}(0.20 \mathrm{~mol} /$ $\left(\mathrm{m}^{3}\right)$.

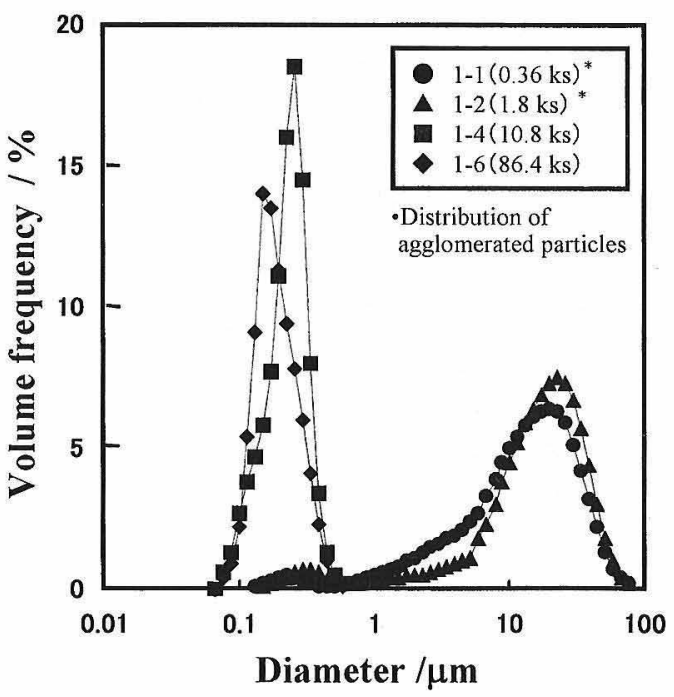

Fig. 5. Particle size distributions of precipitates sampled after different aging time. Starting solutions: $\mathrm{CoCl}_{2} \cdot 6 \mathrm{H}_{2} \mathrm{O}(0.10 \mathrm{~mol} /$ $\left.\mathrm{dm}^{3}\right)$ and $\mathrm{NaOH}\left(0.20 \mathrm{~mol} / \mathrm{dm}^{3}\right)$.

synthesized by using $\mathrm{CoCl}_{2} \cdot 6 \mathrm{H}_{2} \mathrm{O}$ and $\mathrm{NaOH}$ under various precipitation conditions. All the precipitate samples were identified as $\beta-\mathrm{Co}(\mathrm{OH})_{2}$ by XRD.

Platelets with $\sim 0.3$ (sample 2-1) and $\sim 0.5 \mu \mathrm{m}(2-2)$ in average diameter were prepared with high reproducibility. Figure 6 gives an SEM micrograph of sample 2-2. The micrograph of sample $2-1$ was quite similar to the precipitates as shown in Fig. 1 . The $\beta-\mathrm{Co}(\mathrm{OH})_{2}$ were larger 
Table 2. Preparation Conditions and Characteristics of Crystals Obtained in the Precipitation Method

\begin{tabular}{|c|c|c|c|c|c|c|c|c|}
\hline \multirow{2}{*}{$\begin{array}{l}\text { Sample } \\
\text { name }\end{array}$} & \multicolumn{4}{|c|}{ Precipitation conditions } & \multirow{2}{*}{$\begin{array}{l}\text { Aging } \\
\text { temperature } \\
/ \mathrm{K}\end{array}$} & \multicolumn{3}{|c|}{ Characteristics } \\
\hline & $\begin{array}{c}\mathrm{CoCl}_{2} \cdot 6 \mathrm{H}_{2} \mathrm{O} \\
/ \mathrm{mol} \cdot \mathrm{dm}^{-3}\end{array}$ & $\begin{array}{l}\mathrm{NaOH} \\
/ \mathrm{mol}^{-\mathrm{dm}^{-3}}\end{array}$ & $\begin{array}{c}\text { Adding rate of } \\
\mathrm{NaOH} \\
/ 10^{-3} \mathrm{dm}^{3} \cdot \mathrm{s}^{-1}\end{array}$ & $\begin{array}{l}\text { Stirring } \\
\text { rate / rpm }\end{array}$ & & $\begin{array}{c}\text { Crystalline } \\
\text { phase }\end{array}$ & $\begin{array}{l}\text { Ave. particle } \\
\text { size } / \mu \mathrm{m}\end{array}$ & $\begin{array}{l}\text { Ave. aspect } \\
\text { ratio }\end{array}$ \\
\hline $2-1$ & 0.10 & 0.20 & 0.25 & 160 & R.T. & $\beta-\mathrm{Co}(\mathrm{OH})_{2}$ & 0.3 & 5 \\
\hline $2-2$ & 0.025 & 0.025 & 0.25 & 160 & R.T. & $\beta-\mathrm{Co}(\mathrm{OH})_{2}$ & 0.5 & 5 \\
\hline $2-3$ & 0.10 & 0.2 & 0.17 & 160 & R.T. & $\beta-\mathrm{Co}(\mathrm{OH})_{2}$ & 0.3 & 5 \\
\hline $2-4$ & 0.10 & 0.2 & 0.083 & 160 & R.T. & $\beta-\mathrm{Co}(\mathrm{OH})_{2}$ & 0.3 & 5 \\
\hline $2-5$ & 0.10 & 0.2 & 0.25 & 40 & R.T. & $\beta-\mathrm{Co}(\mathrm{OH})_{2}$ & 0.3 & 5 \\
\hline $2-6$ & 0.10 & 0.2 & 0.25 & 320 & R.T. & $\beta-\mathrm{Co}(\mathrm{OH})_{2}$ & 0.3 & 5 \\
\hline $2-7$ & 0.10 & 0.2 & 0.25 & 160 & 323 & $\beta-\mathrm{Co}(\mathrm{OH})_{2}$ & 0.2 & $-2)$ \\
\hline
\end{tabular}

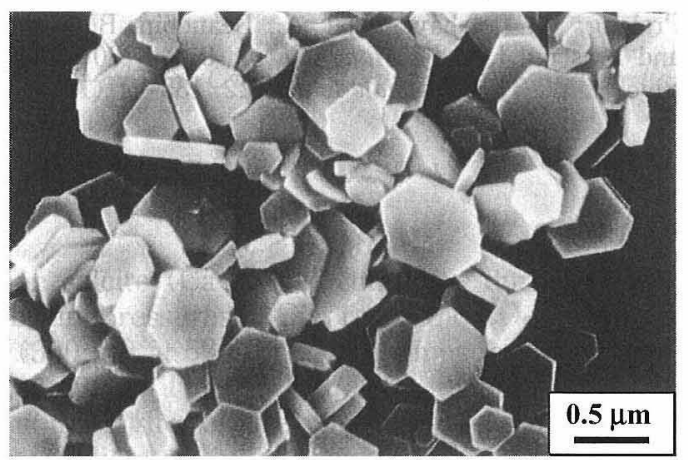

Fig. 6. SEM micrograph of $\beta$ - $\mathrm{Co}(\mathrm{OH})_{2}$ prepared by the precipitation method with the use of $\mathrm{CoCl}_{2} \cdot 6 \mathrm{H}_{2} \mathrm{O}\left(0.025 \mathrm{~mol} / \mathrm{dm}^{3}\right)$ and $\mathrm{NaOH}\left(0.050 \mathrm{~mol} / \mathrm{dm}^{3}\right)$ as starting solutions.

( $\sim 0.5 \mu \mathrm{m}$ ) when prepared from the solution at lower cobalt ion concentration $\left(0.025 \mathrm{~mol} / \mathrm{dm}^{3}\right)$. The increase in the particle size is attributable to the decreased number of $\beta$ - $\mathrm{Co}(\mathrm{OH})_{2}$ nucleus due to the low concentration of cobalt ion.

Adding rate of precipitant did not influence the appearance of crystals (samples 2-1, 2-3 and 2-4) although it is expected that the rate might control the primary nucleation and hence the crystal growth of $\beta-\mathrm{Co}(\mathrm{OH})_{2}$. Stirring rate is well known to affect crystal growth in some cases, however, there appeared little influence on the size of $\beta$ - $\mathrm{Co}(\mathrm{OH})_{2}$ particles (samples 2-1, 2-5, and 2-6). Higher stirring rate and slower adding rate might improve uniformity of particle size, because one can expect that primary nucleation might occur more uniformly in these conditions. Higher aging temperature (sample $2-7$, at $323 \mathrm{~K}$ ) gave slightly diminished particles size and rather equiaxally shaped particles. Increasing temperature would be improper to prepare $\beta$ - $\mathrm{Co}(\mathrm{OH})_{2}$ platelets with developed facets.

All the precipitated platelets had similar aspect ratio, and $\{001\}$ plane developed. In $\beta$ - $\mathrm{Co}(\mathrm{OH})_{2}$, the $\{001\}$ plane is oxygen closed packed with the lowest surface energy, so that a crystal tends to grow with preferred $\{001\}$ facets. The size and aspect ratio of the crystals were not varied in the range of precipitation conditions in this work.

3.4 Hydrothermal treatment of $\beta$ - $\mathrm{Co}(\mathrm{OH})_{2}$ platelets

Figure 7 gives an SEM micrograph of the particles (hexagonal shape, $5-10 \mu \mathrm{m}$ in diameter, $\sim 5$ in aspect ratio) prepared by hydrothermal treatment (at $393 \mathrm{~K}$ for $86.4 \mathrm{ks}$ in 12

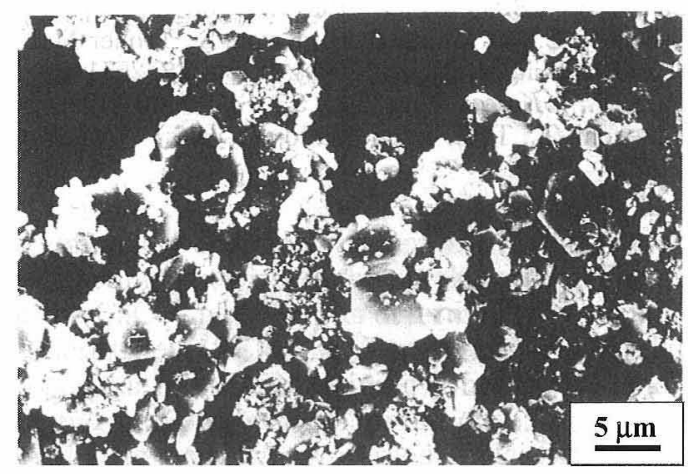

Fig. 7. SEM micrograph of $\beta-\mathrm{Co}(\mathrm{OH})_{2}$ treated under hydrothermal conditions (at $393 \mathrm{~K}$ for $86.4 \mathrm{ks}$ in $12 \mathrm{~mol} / \mathrm{dm}^{3} \mathrm{NaOH}$ aqueous solution).

$\mathrm{mol} / \mathrm{dm}^{3} \mathrm{NaOH}$ aqueous solution $)$ of $\beta-\mathrm{Co}(\mathrm{OH})_{2}(\sim 0.3 \mu \mathrm{m}$ in diameter, $\sim 5$ in aspect ratio). The XRD peaks of the prepared platelets were assigned for $\beta-\mathrm{Co}(\mathrm{OH})_{2}$ as a dominant phase with a small amount of $\mathrm{Co}_{3} \mathrm{O}_{4}$. The latter phase was considered to be due to air contained in the autoclave. Since cobalt hydroxide partially dissolves into the dense basic solution, smaller crystals tend to dissolve and the growth of larger crystals is accelerated by solution-reprecipitation, which result in crystals $(5-10 \mu \mathrm{m}$ in diameter) were formed with maintained morphology (hexagonal shape, $\sim 5$ in aspect ratio).

Many small particles (less than $\sim 0.3 \mu \mathrm{m}$ ) still remained under the conditions in this study. Optimized conditions (temperature, treating time, $\mathrm{pH}$, and atmosphere, etc.) would produce $\beta$ - $\mathrm{Co}(\mathrm{OH})_{2}$ platelets with desired size and developed facets.

\section{Conclusions}

Hexagonal platelets of $\beta$-Co $(\mathrm{OH})_{2}$ were synthesized with high crystallinity by the precipitation and hydrothermal methods. In the precipitation method, the platelets with 0.3 and $0.5 \mu \mathrm{m}$ in average diameter and $\sim 5$ in aspect ratio were prepared by changing the concentration of cobalt ion ranged from 0.10 to $0.025 \mathrm{~mol} / \mathrm{dm}^{3}$. Adding rate of precipitant, stirring rate of the suspension, and aging temperature showed little influence. The platelets of $\beta-\mathrm{Co}(\mathrm{OH})_{2}$ were synthesized with high reproducibility, when chloride salt was used as a Co-source, while the use of nitrate salt tended to give $\mathrm{CoO}(\mathrm{OH})$ and $\mathrm{Co}_{3} \mathrm{O}_{4}$ particles. Insufficient aging time gave 
agglomerated precipitates with undeveloped facets, however, the aging time of $86.4 \mathrm{ks}$ was sufficient for the preparation of discrete particles with developed facets. The sizes of $\beta-\mathrm{Co}(\mathrm{OH})_{2}$ platelets were enlarged up to $5-10 \mu \mathrm{m}$ with maintained their morphology by hydrothermal treatment. The platelets obtained in this study are expected to be useful as reactive templates (precursors) for the fabricating of thermoelectric cobaltite materials, because of their high crystallinity and anisometry. The development of optimal templates for RTGG process is presently under investigations.

Acknowledgements Authors would like to thank Mr. Naoyoshi Watanabe and Ms. Minako Uoshima of Toyota CRDL, Inc., for sample preparation and SEM observation.

\section{References}

1) Hirao, K., Ohashi, M., Brito, M. E. and Kanzaki, S., J. Am. Ceram. Soc., 78, 1687-90 (1995)

2) Seabaugh, M. M., Kerscht, I. H. and Messing, G. L., J. Am. Ceram. Soc., 80, 1181-88 (1997).

3) Sobolsky, E. M., James, A. R., Kwon, S., Trolier-McKinstry, S. and Messing, G. L., Appl. Phys. Lett., 78, 2551-53 (2001).

4) Tani, T., J. Korean Phys. Soc., 32, S1217-20 (1998).

5) Takeuchi, T., Tani, T. and Saito, Y., Jpn. J. Appl. Phys., 38,
$5553-56$ (1999).

6) Kimura, T. and Yamaguchi, T., Ceram. Int., 9, 13-17 (1983).

7) Takeuchi, T., Tani, T. and Satoh, T., Solid State Ionics, 108, 67-71 (1998)

8) Watari, K., Brahmaroutu, B., Messing, G. L., TrolierMcKinstry, S. and Cheng, S. C., J. Mater. Res., 15, 846-49 (2000).

9) Sugawara, T., Nomura, Y., Kimura, T. and Tani, T., J. Ceram. Soc. Japan, 109, 897-900 (2001).

10) Takeuchi, T. and Tani, T., Key Eng. Mater., 216, 3-6 (2002).

11) Hirota, E., Kugimiya, K. and Nishio, T., J. Jpn. Soc. Powder and Powder Metall., 26, 123-30 (1979) [in Japanese].

12) Tajima, S., Tani, T., Isobe, S. and Koumoto, K., Mater. Sci. Eng., B86, 20-25 (2001).

13) Fujita, K., Mochida, T. and Nakamura, K., Jpn. J. Appl. Phys. Part 1, 40, 4644-47 (2001).

14) Terasaki, I., Sasago, Y. and Uchinokura, K., Phys. Rev., B56, R12685-87 (1997).

15) Funahashi, R., Matsubara, I., Ikuta, H., Takeuchi, T. Mizutani, U. and Sodeoka, S., Jpn. J. Appl. Phys., 39, L1127-29 (2000).

16) Pralong, V., Delahaye-Vidal, A., Beaudoin, B., Gerand, B. and Trascon, J.-M., J. Mater. Chem., 9, 955-60 (1999).

17) Reichle, W. T., Solid State Ionics, 22, 135-41 (1986). 